\section{Die DRG bei der 101. Jahrestagung GERMANY der RSNA in Chicago}

Vom 29. November bis 4. Dezember fand in Chicago, USA, die 101. Jahrestagung der Radiological Society of North America (RSNA) statt. Mit Deutschland und Mexiko als Gastländer war auch die Deutsche Röntgengesellschaft (DRG) vertreten.

Unter dem Motto „Germany presents at RSNA“ gab es neben einem eigenen DRGStand auch mehrere Vorträge mit ausgewählten Referenten. Bei der Eröffnung der Vortragsreihe am 30. November wurden die Kongressteilnehmer mit auf eine virtuelle Reise ins ferne Remscheid-Lennep, zu den Wurzeln von Wilhelm Conrad Röntgen genommen. Feierlich eröffnet wurde das Programm mit dem Kurzfilm „Röntgen - An X-Ray Journey“ (www.roentgen-gebuertshaus.de > Aktuelles $>$ Der Film zum Haus). Prof. Dr. Norbert Hosten (Greifswald) hielt dazu die Eröffnungsrede und wies darin auf die Bedeutung der historischen Wurzeln der Radiologie hin.

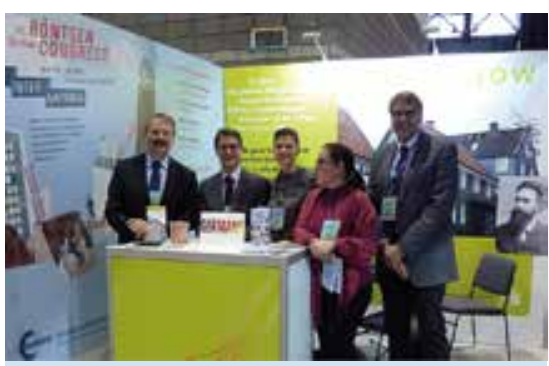

Abb. 1 Der Stand der DRG auf dem diesjährigen RSNA in Chicago. Dr. Stefan Lohwasser, Dr. Martin Völker, Vesselina Minkova und Ulrike Schiedt von der DRG standen gemeinsam mit Dr. Uwe Busch vom Röntgen-Museum den Teilnehmern Frage und Antwort rund um Geburtshaus, RöKo \& Co.

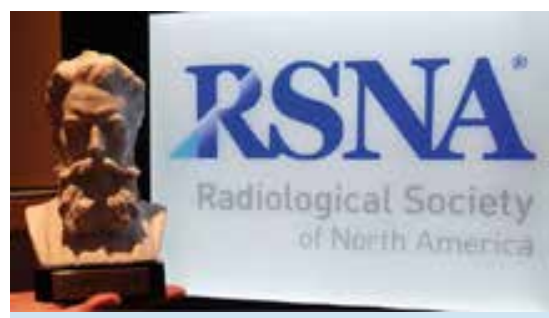

Abb. 2 Herr Röntgen war ebenfalls mit dabei. Ihm war eine ganz besondere Rolle zugedacht.

Der wissenschaftliche Teil der Veranstaltung sollte hingegen die künftigen Anwendungen der medizinischen Bildgebung präsentieren. „Unser Programm hat die Kongressteilnehmer über die nationale Kohortenstudie informiert und deren Wichtigkeit unterstrichen“, versichert

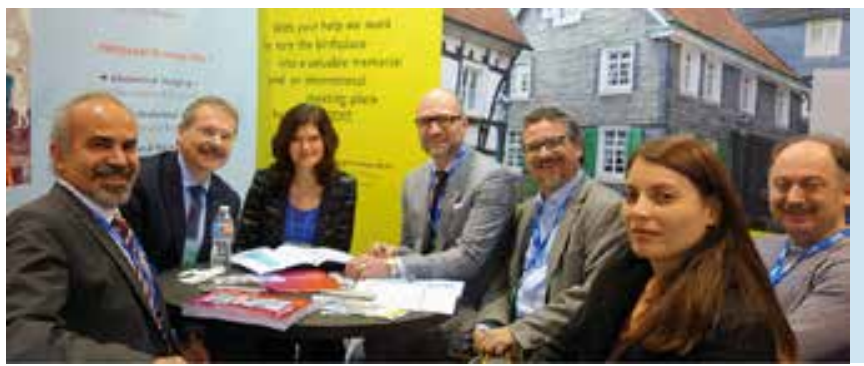

Abb. 4 Es gab viel Gelegenheit zum internationalen Austausch. Hier das Treffen mit der Türkischen Society of Radiology am Stand der DRG am RSNA. li. Türkischer Präsident Prof. Dr. Tamer Kaya.

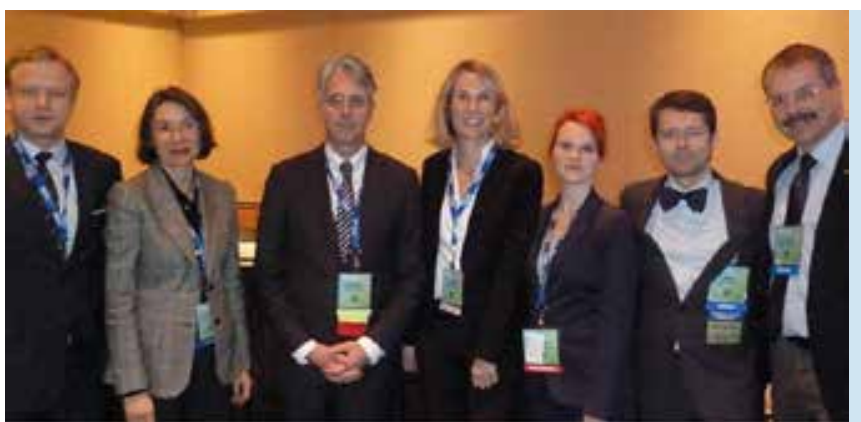

Abb. 5 Germany presents: Das Team. v. li Fabian Bamberg (Tübingen), Gabriele Krombach (Gießen), Norbert Hosten (Greifswald), Sabine Weckbach (Heidelberg), Kathrin Hegenscheid (Berlin), Marc Dewey (Berlin), Stefan Lohwasser (Berlin). 